\title{
Optimization of Integration Plate for LASER Based Range Finding System using FEM
}

\author{
Tarun Kumar Dhiman, Pankaj Negi, Kiran Sharma, Gagan Bansal
}

\begin{abstract}
The design and analysis of an integration plate for Laser Based Range Finding System (LBRFS) is based on three subsystems which are going to be (payload) mounted on different locations. FEM modeling and simulation of three different configurations have been considered for integration plate in assembled payload conditions. Structural analysis of the plate under the simulated boundary conditions was carried out. Plate deflection at critical point was worked out. Depending upon the results obtained optimum plate thickness with stiffeners at the various locations was incorporated on the integration plate to meet the system requirements.
\end{abstract}

Keywords: Laser Based Range Finding System, payload.

\section{INTRODUCTION}

The range finding systems find wide application in meteorology, air pollution monitoring and control, military application, surveying application, oceanography etc. Unlike micro wave radar, laser beam is highly directive and can be used to measure the range of small targets. For survey purpose highly accurate range finding systems with maximum accuracy are available based on laser. The basic principle of laser range finder is to measure (to \& fro) travel time of laser radiations (light) between range finder and object. If " $\mathrm{d}$ " is the distance of target from range finder and " $t$ " is the time for travel of light (to and fro path), and "c" speed of light, then $\mathrm{t}=2 \mathrm{~d} / \mathrm{c}$ and distance, $\mathrm{d}=\mathrm{ct} / 2$.

Following are the different types of subsystems of Laser based range finding system:

1. Trans-receiver Module

2 Ranging and display Module

3. Power Supply Module

As all the above subsystems are going to be mounted on an integration plate. The design and analysis of this integration plate is quite critical from the system performance point of view. The design optimization of this plate has been carried out taking into consideration all the above three subs systems (payloads), system requirements, and working conditions. Analysis of the plate for deflection at various critical points caused by different subsystems under static and dynamic conditions was carried out using CAD tools. Taking into consideration the size, weight, and system requirements necessary supporting ribs/mechanical structure were incorporated to minimize the deflection at critical points within acceptable limits.

Revised Manuscript Received on September 25, 2019.

Tarun Kumar Dhiman, Department of Mechanical Engineering, Graphic Era Hill University, Dehradun, Uttarakhand, India.

Pankaj Negi, Department of Mechanical Engineering, Graphic Era Hill University, Dehradun, Uttarakhand, India.

Kiran Sharma, Department of Physics, Graphic Era deemed to be University, Dehradun, Uttarakhand, India.

Gagan Bansal, Department of Mechanical Engineering, Graphic Era deemed to be University, Dehradun, Uttarakhand, India.
[1] Vibration analysis and stability investigation of plates having mixed edge condition were conducted. [2] Series type method was used for free vibration of an orthotropic elastically constrained plate. [3] Finite strip method was used to model large deflection of plate using modified Newton-Raphson method. [4] Vibration and buckling of thin strips with mixed boundary condition using spline element method was used. [5] Generalized differential quadratic method was used and natural frequency of plate was obtained. [6] Incorporating stress singularity-based methodology for vibration analysis was considered. [7] Galerkins method was used to simulate the effect of inertia and shear deformation. [10] Evaluation of mixed and nonuniform boundary condition using generalized quadrature method was performed. [11] Free transverse vibration of rectangular plate with all boundary condition was simulated using Rayleigh method. [12] Ritz method was applied and the effect of changing Poisson ratio was studied. [13] Discrete and singular convolution algorithm was used for solving equation. [14] Study on flexural vibration of anisotropic plates, for this work domain decomposition method was used. [15] Analysis using spline fit strip method was performed. [16] Comprehensive analytical technique was used for free vibration analysis. [17] Vibrational analysis was performed using discrete singular convolution algorithm.

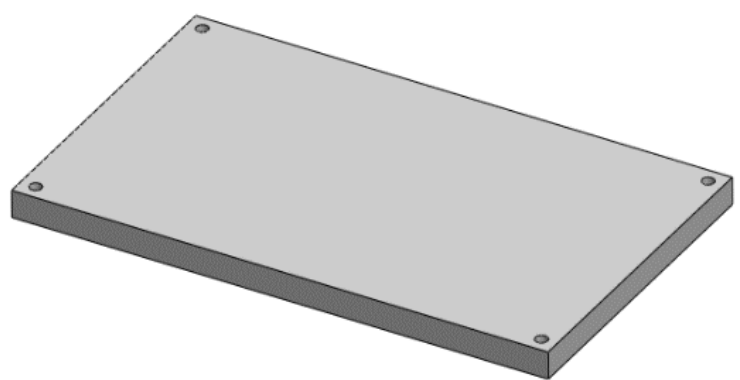

Fig.1: Integration Plate

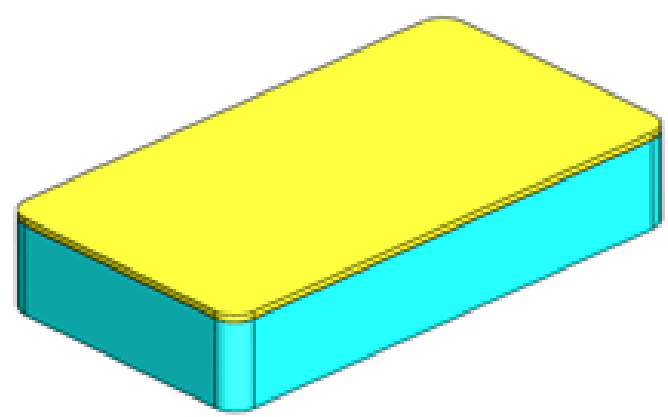

Fig.2: Dummy Load-1(4.5 Kg)

Published By:

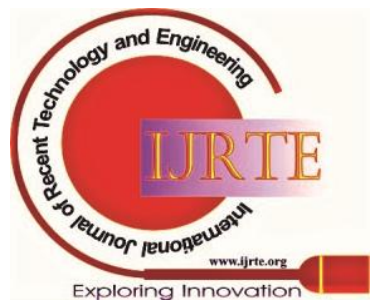



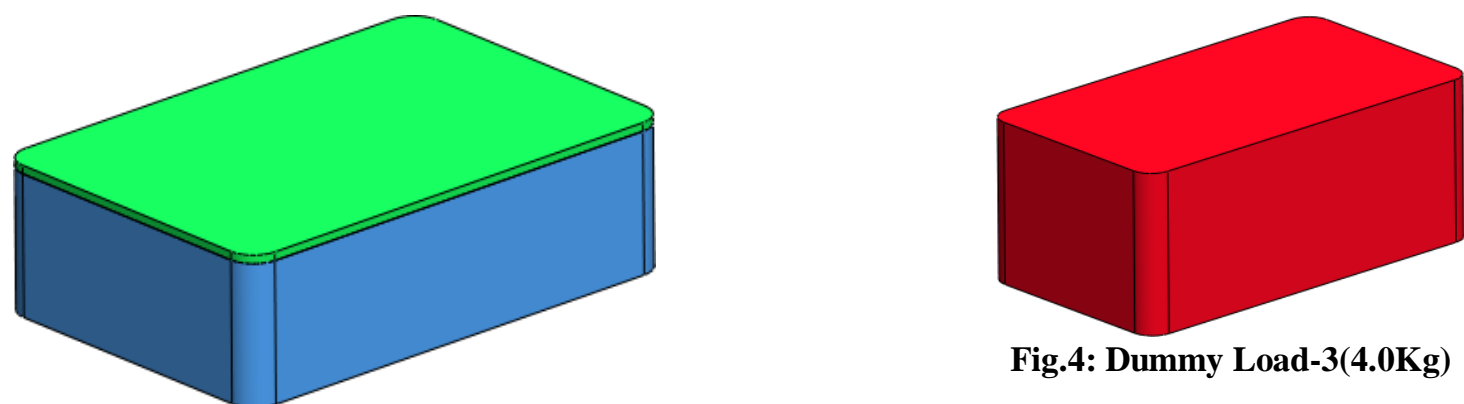

Fig.4: Dummy Load-3(4.0Kg)

Fig.3: Dummy Load-2(3.5 Kg)

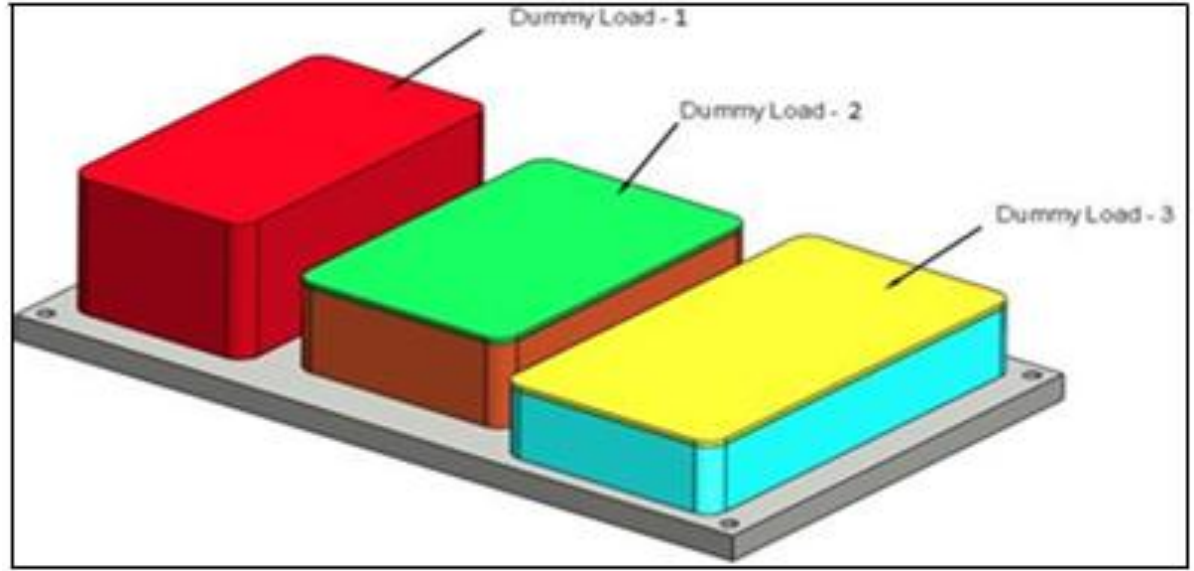

Fig.5: Assembly of Dummy Loads over Integration Plate

Integration plate model is design using CAD. Length and width of plate is around $350 \mathrm{~mm}$ and $210 \mathrm{~mm}$. All three payloads were design and simulation is done after mounting over integration plate.

The governing equation for Eigen value analysis of the system may be cast in matrix form such that $\mathrm{M} \partial^{2} \mathrm{x} / \partial \mathrm{t}^{2}$ $+$ $\mathrm{Kx}$ $=$

\section{(1)}

Where $\mathrm{M}$ and $\mathrm{K}$ are the $\mathrm{N} \times \mathrm{N}$ matrices, containing mass and stiffness terms, Considering the homogeneous part of Equation (1) and assuming that the displacement response isharmonic,

\section{$\mathrm{X}(\mathrm{t})=\mathrm{X}(\omega)$}

$\mathrm{e}^{\mathrm{i} \omega \mathrm{t}}$

\section{.... (2)}

The structural Eigen problem can be written in the form,

$\mathrm{K} \phi_{\mathrm{j}}=\lambda_{\mathrm{j}}$ $\mathrm{M} \quad \phi_{\mathrm{j}}, \quad \mathrm{j}=1, \quad 2, \quad 3$,

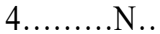
(3)

Where $\lambda j=\omega j 2 \quad$ is the $j$ th Eigen vector .Solving the above equation we can find out that natural frequency and mode shape of any system .after simulation of weight and Centre of gravity (CG) of the entire three system payload using Solid Works, models were finalized. The design analysis was carried out using Solid Works Simulation Express. After creation of finite element mesh, elements have been checked for distortion, skew ness etc. for acceptability. Materials were assigned for different components. After assigning the material properties, boundary conditions were applied as per actual conditions. Model analysis was performed by solving the above Eigen value problem. The results were displayed using postprocessing and on the basis of FEA results modifications were incorporated to meet the system requirements of less than 50micron deflection. Details of modeling and processing of different components are discussed in subsequent paragraph.

Subsystems modeling were done such that mass and Centre of gravity of actual system were retained. The modeling of the components was done by using Solid Works software and model was then imported to solid works simulation express through Initial Graphics Exchange Specification (LGES) file for the model analysis using finite element method. To achieve the optimum design of the integration plate three different configurations have been considered for the analysis of the plate in assembled payload conditions. FEM analysis was carried out to analyze the stresses developed, normal frequency and deflection of plate. The following plate configurations have been considered Configuration 1- Plate with uniform thickness of $15 \mathrm{~mm}$ Configuration 2- Plate with thickness of $15 \mathrm{mmwith} 4 \mathrm{~mm}$ ribs and material squibbed at different locations

Configuration 3- Plate with thickness of $15 \mathrm{~mm}$ with $7 \mathrm{~mm}$ ribs and material squibbed at different locations

\section{BOUNDARY CONDITIONS}

The integration plate has been fixed using four holes of diameter $8.2 \mathrm{~mm}$ to constrain the motion in all six degree of freedoms i.e. three rotation and three translation Each subsystem payload has been mounted on the integration plate with the help of four M4 fasteners. These entire subsystems payload have been mounted on the integration plate as shown in figure 5 .

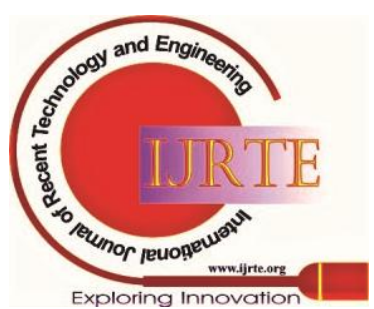


The 3D solid model and wire frame CAD model of integration plate. The design analysis has been carried out using Solid Works Simulation Express. The meshed integration plate is shown in figure 6. The details of component material, type of elements, and meshing are given below.

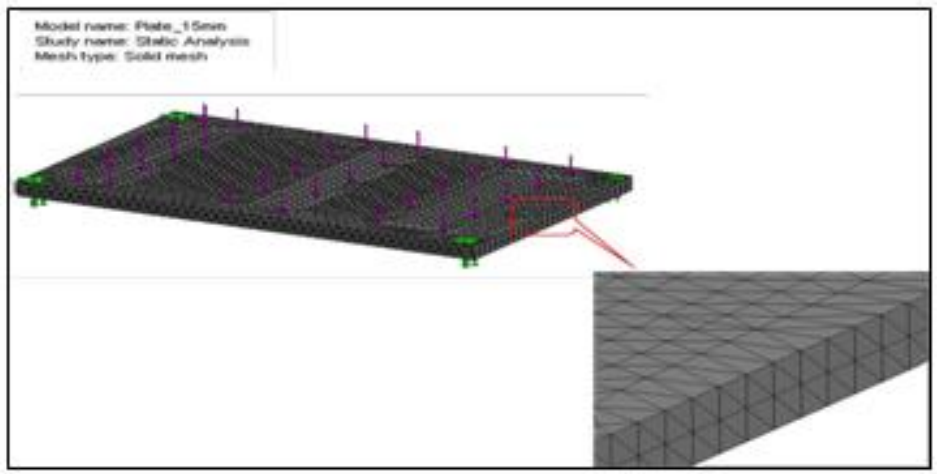

Fig. 6 Meshed Integration plate

\section{FREQUENCY ANALYSIS OF PLATE_15MM_@6G}

Material specifications used for analysis of LASER Integration plate.

Table: 1(Material Properties)

\begin{tabular}{|l|l|l|}
\hline Material name: & \multicolumn{1}{|l|}{ Aluminum Alloy - 2219-T31 } & \\
\hline \hline Property Name & Value & Units \\
\hline \hline Elastic modulus & $7.2 \mathrm{e}+010$ & $\mathrm{~N} / \mathrm{m}^{\wedge} 2$ \\
\hline \hline Poisson's ratio & 0.33 & $\mathrm{NA}$ \\
\hline \hline Shear modulus & $2.7 \mathrm{e}+010$ & $\mathrm{~N} / \mathrm{m}^{\wedge} 2$ \\
\hline \hline Mass density & 2840 & $\mathrm{~kg} / \mathrm{m}^{\wedge} 3$ \\
\hline \hline Tensile strength & $3.6 \mathrm{e}+008$ & $\mathrm{~N} / \mathrm{m}^{\wedge} 2$ \\
\hline \hline Yield strength & $2.5 \mathrm{e}+008$ & $\mathrm{~N} / \mathrm{m}^{\wedge} 2$ \\
\hline \hline Thermal expansion coefficient & $2.23 \mathrm{e}-005$ & $/ \mathrm{Kelvin}$ \\
\hline \hline Thermal conductivity & 116 & $\mathrm{~W} /(\mathrm{m} . \mathrm{K})$ \\
\hline \hline Specific heat & 864 & $\mathrm{~J} /(\mathrm{kg} . \mathrm{K})$ \\
\hline
\end{tabular}

\section{Restraints and Loads}

Table: 2 (Restraints)

\begin{tabular}{|l||l|}
\hline Restraint name & Selection set \\
\hline \hline Restraint-1 & \multirow{2}{*}{ All Holes $\varnothing 8.0$ are fixed } \\
\hline \hline Restraint-2 & \\
\hline \hline Restraint-3 & \\
\hline \hline Restraint-4 & \\
\hline
\end{tabular}

Table: 3(Load)

\begin{tabular}{|l|l|}
\hline Load name & Selection set \\
\hline \hline Force-1 & Normal force on Top surface $=264.87 \mathrm{~N}$ \\
\hline \hline Force-2 & Normal force on Top surface $=206.01 \mathrm{~N}$ \\
\hline \hline Force-3 & Normal force on Top surface= 235.44 N \\
\hline
\end{tabular}


Table: 4(Mesh Details)

\begin{tabular}{|l|l||}
\hline Mesh Type: & Solid Mesh \\
\hline \hline Method Used: & Standard \\
\hline \hline Automatic Transition: & Off \\
\hline \hline Smooth Surface: & On \\
\hline \hline Size: & $10.323 \mathrm{~mm}$ \\
\hline \hline Tolerance: & $0.51618 \mathrm{~mm}$ \\
\hline \hline Quality of Mesh: & High \\
\hline \hline Elements: & 8651 \\
\hline \hline Nodes: & 14919 \\
\hline
\end{tabular}

Plate, 15mm@6g-Deformation1

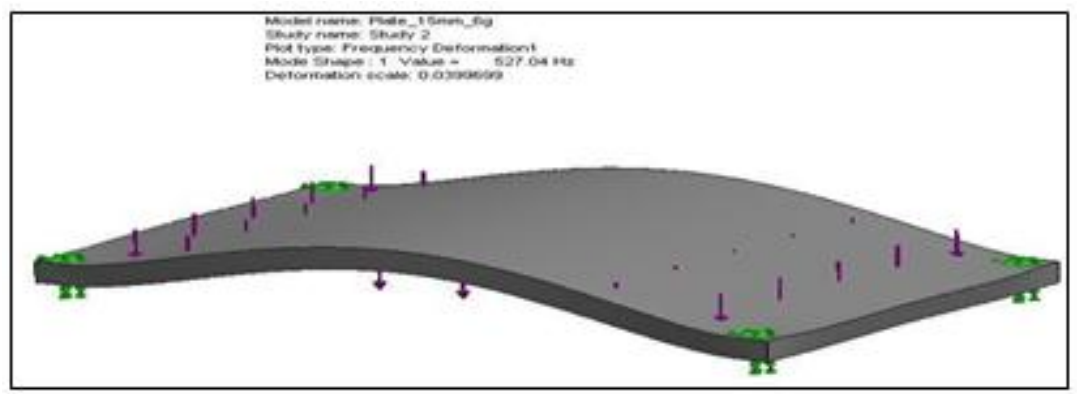

Fig. 7: Frequency analysis result-1

Plate, 15mm @6g-Deformation2

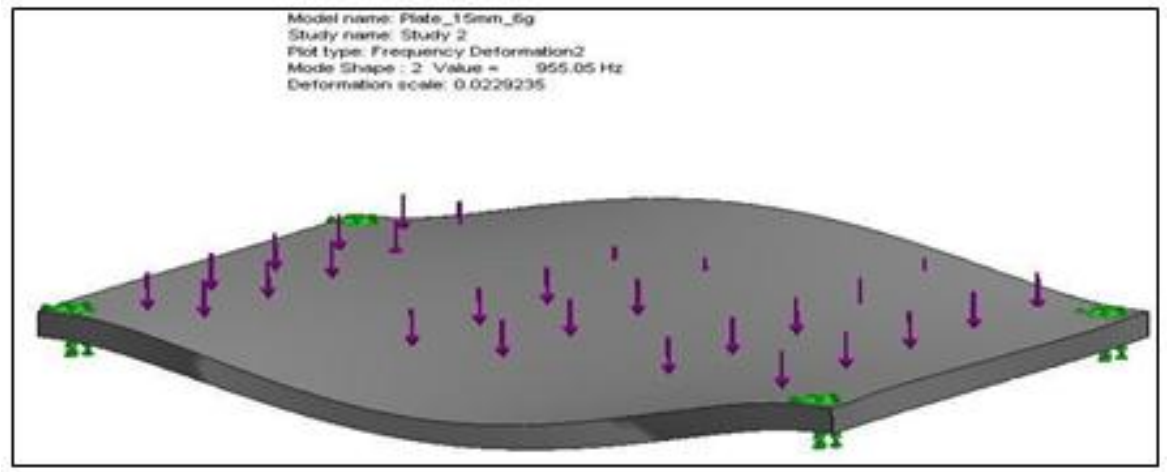

Fig. 8: Frequency analysis result -2

IV. FREQUENCY ANALYSIS OF PLATE, 15MM WITH RIB DEPTH 4MM) @6G (SAME MATERIAL)

Table: 5 (Restraints)

\begin{tabular}{|l|l|}
\hline Restraint name & Selection set \\
\hline \hline Restraint-1 & \multirow{2}{*}{ All Holes $\varnothing 8.0$ are fixed } \\
\hline \hline Restraint-2 & \\
\hline \hline Restraint-3 & \\
\hline \hline Restraint-4 & \\
\hline
\end{tabular}

Table: 6 (Load)

\begin{tabular}{|l|l|l|l||}
\hline Load name & Selection set \\
\hline \hline Force-1 & Normal force on Top surface=264.87 \\
\hline val Number: B10180982S1219/2020@BEIESP & $\begin{array}{l}\text { Published By: } \\
\text { Blue Eyes Intelligence Engineering } \\
\text { \& Sciences Publication }\end{array}$
\end{tabular}




\begin{tabular}{|l|l||}
\hline Force-2 & Normal force on Top surface $=206.01 \mathrm{~N}$ \\
\hline \hline Force-3 & Normal force on Top surface= 235.44 N \\
& \\
\hline
\end{tabular}

Plate, 15mm with rib (depth4mm) @6g - Deformation1

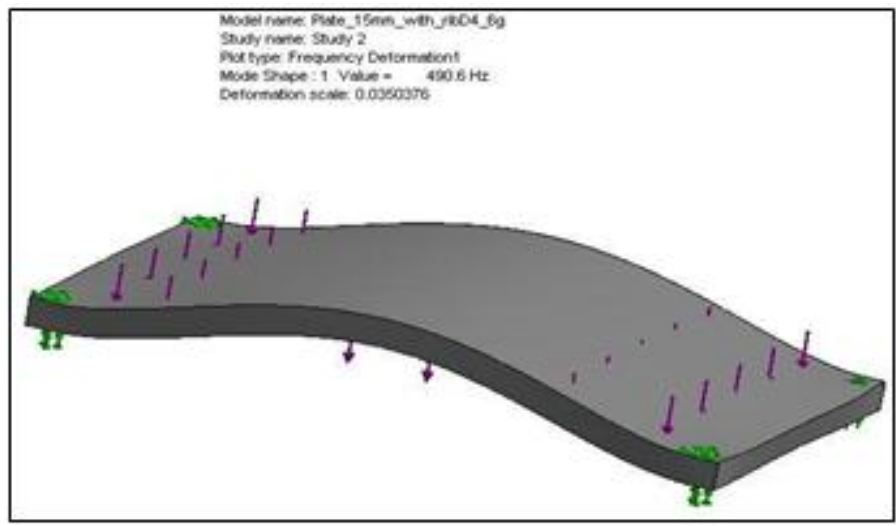

Fig. 9: Frequency analysis result-1

Plate, 15mm with rib (depth4mm) @6g-Deformation2

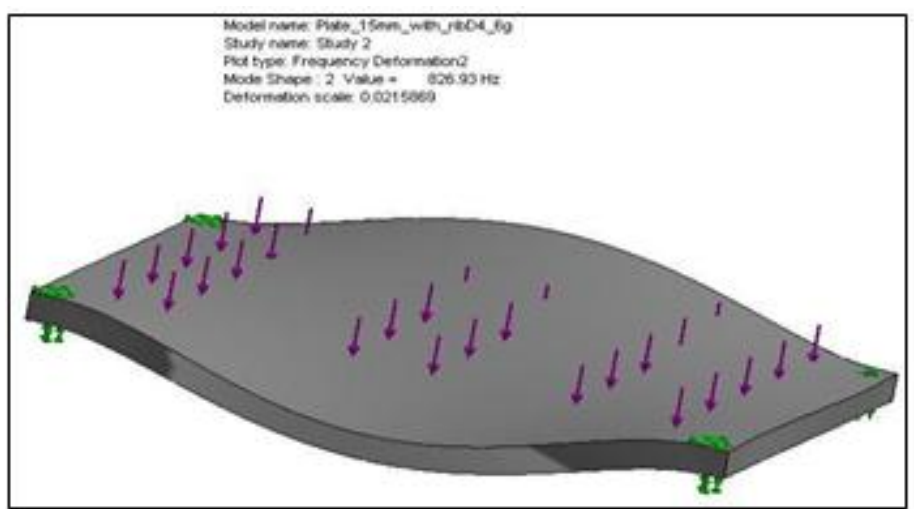

Fig. 10: Frequency analysis result-2

V. FREQUENCY ANALYSIS OF PLATE, 15MM WITH RIB (DEPTH7MM) @6G (SAME MATERIAL)

Table: 7 (Restraint)

\begin{tabular}{|l||l||}
\hline Restraint name & Selection set \\
\hline \hline Restraint-1 & All Holes $\varnothing 8.0$ are fixed \\
\hline \hline Restraint-2 & \\
\hline \hline Restraint-3 & \\
\hline \hline Restraint-4 & \\
\hline
\end{tabular}

Table: 8 (Load)

\begin{tabular}{|l||l||}
\hline Load name & Selection set \\
\hline \hline Force-1 & Normal force on Top surface= 264.87 N \\
\hline \hline Force-2 & Normal force on Top surface= 206.01 N \\
\hline \hline Force-3 & Normal force on Top surface= 235.44 N \\
\hline
\end{tabular}


Plate 15mm with rib (depth7mm)@6g Deformation 1

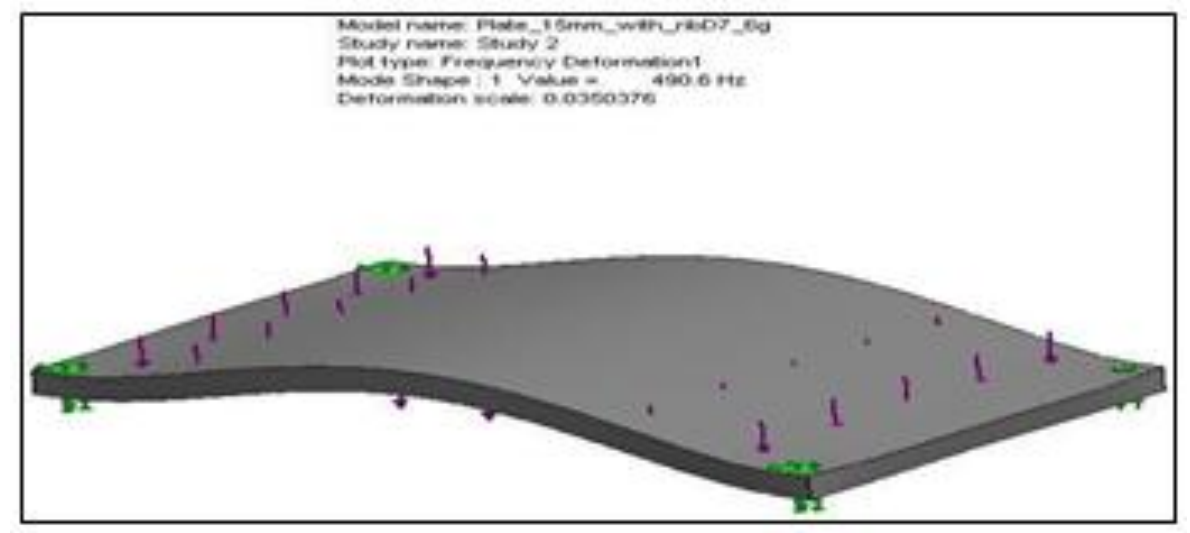

Fig. 11: Frequency analysis result-1

Plate 15mm with rib (depth7mm)@6g Deformation 2

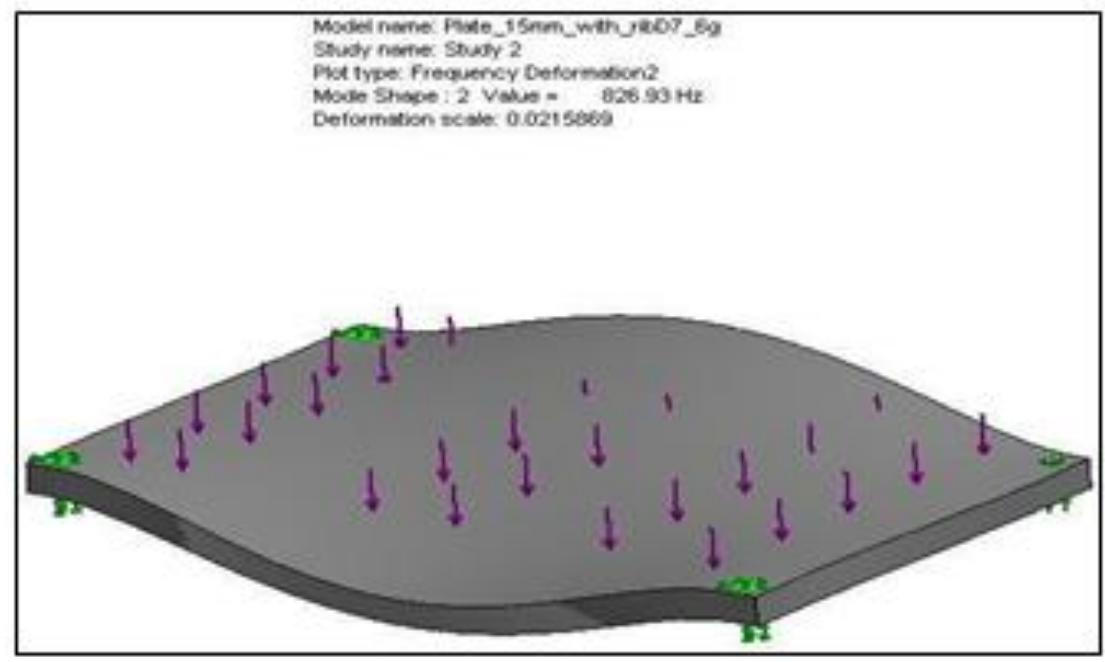

Fig. 12: Frequency analysis result-2

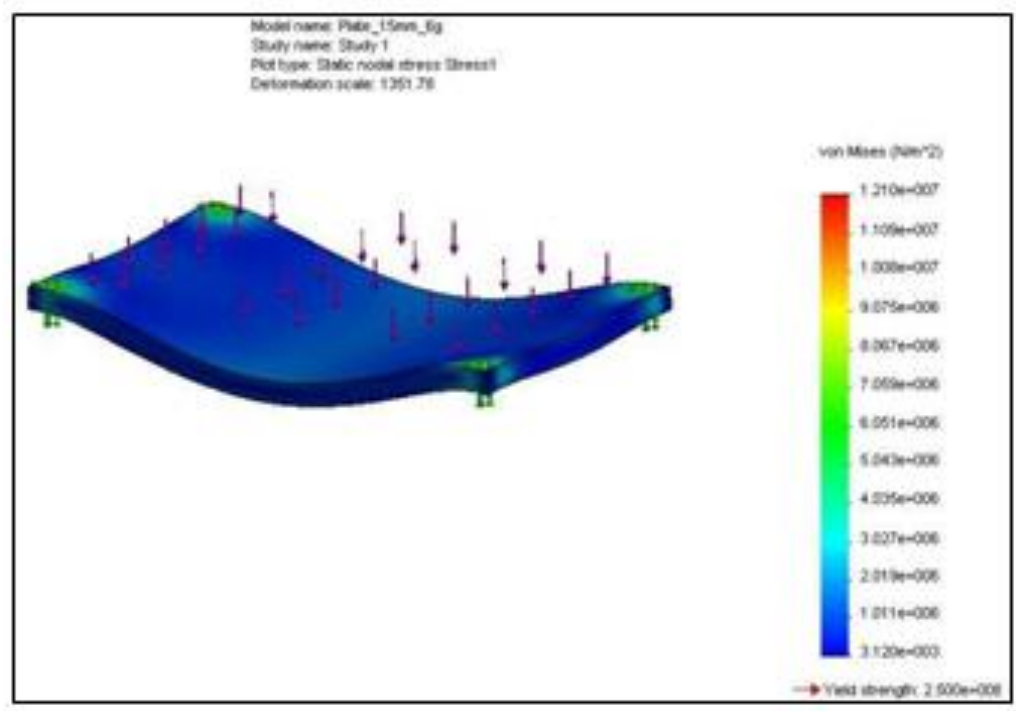

Fig. 13: Stress analysis

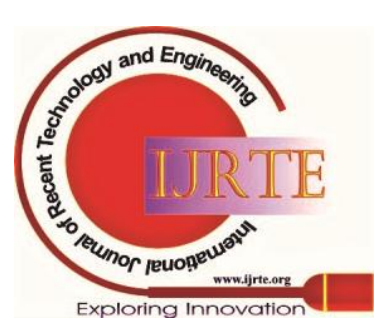




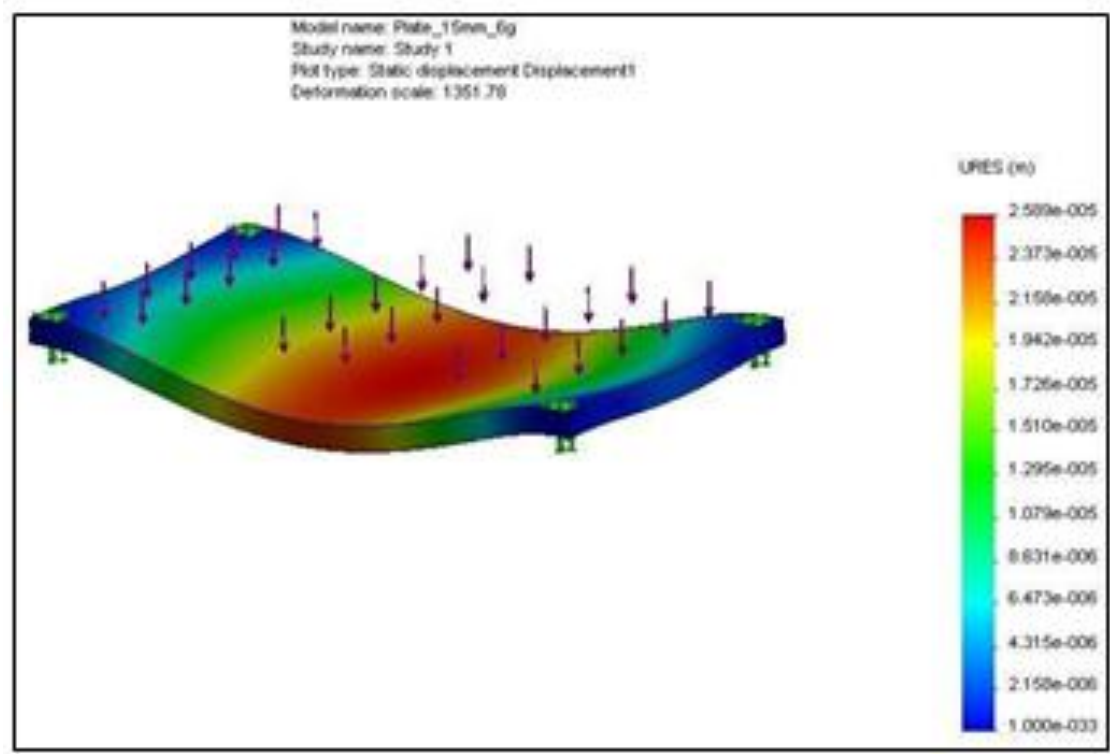

Fig. 14: Displacement analysis

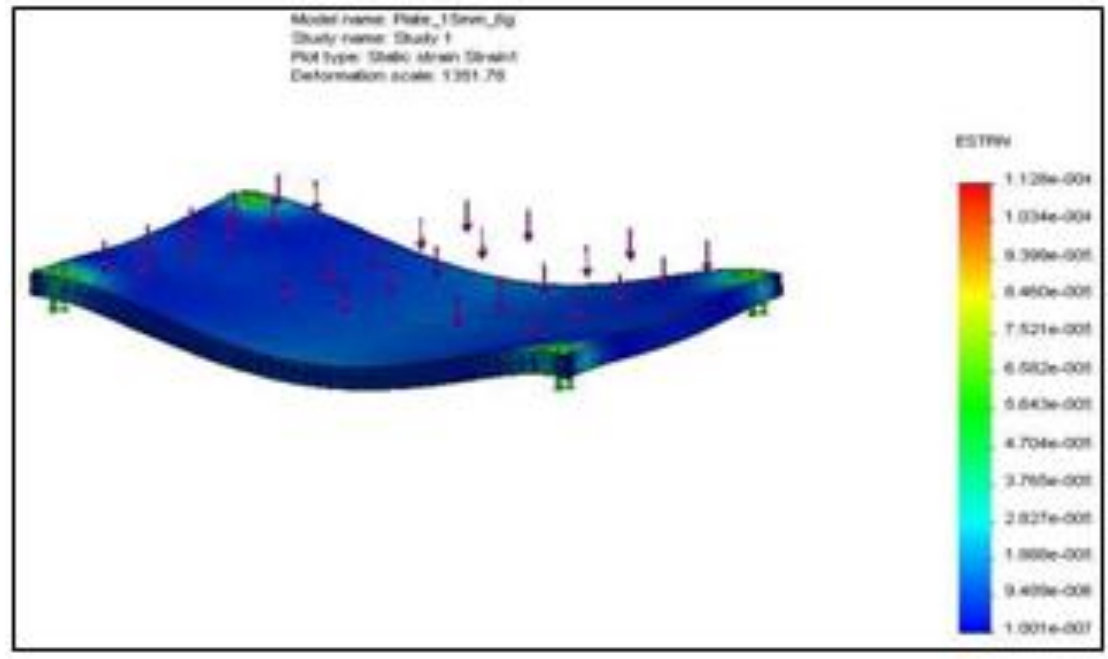

Fig. 15: Strain analysis

Table: 9 (Analysis Report)

\begin{tabular}{|c|c|c|c|c|c|}
\hline Name & Type & Min & Location & Max & Location \\
\hline Stress & $\begin{array}{l}\text { VON: von Misses } \\
\text { Stress }\end{array}$ & $\begin{array}{l}11602.3 \\
\mathrm{~N} / \mathrm{m}^{\wedge} 2 \text { Node: } \\
16523\end{array}$ & $\begin{array}{l}(2.770 \mathrm{~mm}, \\
8.709 \mathrm{~mm}, \\
-96.127 \mathrm{~mm})\end{array}$ & $\begin{array}{l}\text { 1.38e+07 } \\
\text { N/m^2 Node: } 66\end{array}$ & $\begin{array}{l}(336.061 \mathrm{~mm}, \\
0 \mathrm{~mm}, \\
-199.305 \mathrm{~mm})\end{array}$ \\
\hline Displacement & $\begin{array}{l}\text { URES: } \\
\text { Resultant Displacement }\end{array}$ & $\begin{array}{l}0 \mathrm{~m} \\
\text { Node: } 1\end{array}$ & $\begin{array}{l}(10 \mathrm{~mm}, \\
0 \mathrm{~mm}, \\
-196 \mathrm{~mm})\end{array}$ & $\begin{array}{l}\text { 3.76e-05 m } \\
\text { Node: } 6679\end{array}$ & $\begin{array}{l}(178.89 \mathrm{~mm}, \\
9.463 \mathrm{~mm}, \\
-105.061 \mathrm{~mm})\end{array}$ \\
\hline Strain & $\begin{array}{l}\text { ESTRN: } \\
\text { Equivalent Strain }\end{array}$ & $\begin{array}{l}\text { 6.530e-08 } \\
\text { Element: } 14495\end{array}$ & $\begin{array}{l}(8.252 \mathrm{~mm}, \\
8.523 \mathrm{~mm}, \\
-105.086 \mathrm{~mm})\end{array}$ & $\begin{array}{l}0.000118 \\
\text { Element: } 11870\end{array}$ & $\begin{array}{l}(336.843 \mathrm{~mm}, \\
0.846 \mathrm{~mm}, \\
-14.811 \mathrm{~mm})\end{array}$ \\
\hline
\end{tabular}

\section{RESULT AND CONCLUSION:}

FEM analysis of LASER based range finding system was performed. Optimization of integration plate was completed. Three different types of payloads are used over plate for analysis purpose. Model analysis was performed by solving the above Eigen value problem.

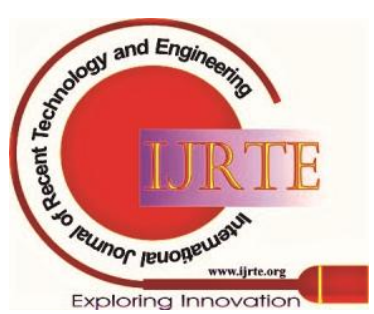


The results were displayed using post processing and on the basis of FEA results modifications were incorporated to meet the system requirements of less than 50micron deflection.

\section{REFERENCE}

1. Keer LM, Stahl B. Eigen value problems of rectangular plates with mixed Boundary conditions. Journal of Applied Mechanics 1972; 39:513-20

2. Narita Y. Application of a series-type method to vibration of orthotropic Rectangular plates with mixed boundary conditions. Journal of Sound and Vibration 1981; 77:345-55

3. CheungMS. Finite Strip analysis of structures. Ph.D. thesis, University of Calgary, 1971

4. Mizusawa T, Kaijita T. Vibration and buckling of rectangular plates with non-uniform elastic constraints in rotation. International Journal of Solid Structures 1986; 23:45-55

5. Rao GV, Raju IS, Murthy TVGK. Vibration of rectangular plates with mixed boundary conditions. Journal of Sound and Vibration 1973; 30:257-60

6. Mizusawa T, Leonard JW. Vibration and buckling of plates with mixed boundary conditions. Engineering Structures 1990; 12:285-90

7. Chia CY. Non linear vibration in anisotropic rectangular plates of non-uniform edge constraints. Journal: Sound and Vibration of 1985; 101:539-50

8. WangX, Bert CW. New approach by applying deferential quadrature in Static and free vibration analysis in beams \& plates. Journal :Sound and Vibration of 1992; 162:566-72

9. Laura PAA, Gutierrez RH. Analysis of vibrating rectangular plates with non-uniform boundary conditions by using the deferential quadrature method. Journal of Sound and Vibration 1994; 173:702-6

10. Shu C, WangCM. Solution of mixed \& non-uniform boundary conditions of GDQ vibration analysis in rectangular plates. Engineering Structures of year 1999; 21:125-34

11. Warburton GB. Vibration in rectangular plates: The Institute of Mechanical Engineering of 1954; 168:371-84

12. Leissa AW. The free vibration of rectangular plates. Journal of Sound and Vibration 1973; 31:257-93

13. Wei GW. Solution to quantum eigen value problems through discrete singular convolution. Journal of Physics B 2000; 33:343-52

14. Liew K M, Hung K C, Lam KY. Substructure method in Vibration analysis for rectangular plates along with noncontinuous boundary Conditions. Journal of Sound and Vibration 1993; 163:451-62

15. Nowacki W, Free vibrations and buckling of a rectangular plate with discontinuous boundary conditions. Bulletin de l'AcadXemie Polonaise des Sciences 1955; 3:159-67

16. Gorman DJ. An exact analytical approach to the free vibration analysis of rectangular plates with mixed boundary conditions. Journal of Sound and Vibration 1984; 93:235-47

17. Piskunov VH. Determination of the frequencies of the natural oscillations of rectangular plates with mixed boundary conditions. Prikladnaya Mekhanika 1964; 10:72-6 [in Ukrainian]

18. Experimental Advanced Research Lidar', NASA.org. Retrieved 8 August 2007

19. Tom Paulson. 'LIDAR shows where earthquake risks are highest, Seattle Post (Wednesday, April 18, 2001) 